\section{The effect of Helicobacter pylori seropositivity and activity on disease outcome in patients with rheumatoid arthritis, systemic lupus erythematosus and ankylosing spondylitis}

\author{
Asmaa E. Hamed ${ }^{1}$, Abdelhfeez Moshrif ${ }^{2}$, Mohamed \\ Ryan $^{2}$, Mona M. Abdelmaguid ${ }^{3}$, Haitham A. Azeem ${ }^{4}$, \\ Mohamed I. Abdelkreem ${ }^{2}$
}

${ }^{1}$ Internal Medicine Department, Sohag General Hospital, Sohag.

${ }^{2}$ Rheumatology Department, Faculty of Medicine, Al Azhar University, Assiut.

${ }^{3}$ Clinical Pathology Department, Faculty of Medicine, Al Azhar University, Assiut.

${ }^{4}$ Internal Medicine Department, Faculty of Medicine, Al Azhar University, Assiut.
The Egyptian Journal of Immunology Volume 28 (4), 2021: 206-214. www.Ejimmunology.org
Corresponding author: Abdelhfeez Moshrif, Rheumatology Department, Faculty of Medicine, Al-Azhar University, Assiut. 71524, Al-Azhar University square, King Faysal, Assiut, Egypt.

Email: dr.moshrif@azhar.edu.eg.

\begin{abstract}
The association between infection with Gram-negative bacteria and autoimmune diseases has been investigated with controversies about the role of the organisms especially, Helicobacter pylori $(H$. pylori). To evaluate the impact of the presence and activity of $H$. pylori on the disease activity in patients with rheumatoid arthritis (RA), systemic lupus erythematosus (SLE) and ankylosing spondylitis (AS). This study was carried out on one hundred adult patients and 50 controls. Patients included 40 RA, 40 SLE, and 20 AS. Participants were subjected to clinical examination and laboratory investigations; ESR (spectrophotometric assay), CRP (turbidimetric method), serum H.pylori IgG antibody test (enzyme immunoassay), and $H$. pylori antigen test (lateral flow immunoassay, rapid onestep test) in stool. Positive test in stool indicated active current $H$. pylori infection. Mean age of patients was $36.95 \pm 10.34 ; 51.2 \pm 6.91,35.5 \pm 3.71$, and $48.82 \pm 5.81$ in SLE, RA, AS, and control groups respectively. Serum $H$. pylori IgG antibodies was $0.803 \pm 0.497 \mathrm{U} / \mathrm{mL}$ in SLE group, $1.48 \pm 0.637 \mathrm{U} / \mathrm{mL}$ in RA group and $0.75 \pm 0.68 \mathrm{U} / \mathrm{mL}$ in AS group while it was $0.2 \pm 0.61 \mathrm{U} / \mathrm{mL}$ in the control group with a significant difference $(P=0.000)$. The $H$. pylori antigen in stool was found positive in $30 \%, 70 \%$ and $20 \%$ of patients of the three groups respectively while it was positive in $10 \%$ of the control group with $P>0.001$. Patients with active SLE (SLEDAI $>3$ ) and RA (DAS-28 >3.2) demonstrated higher frequency of positive test for $H$. pylori antigen in stool than patients at remission $(66.7 \% P=0.02$ and $83.3 \% P=0.01$ respectively). In contrast, $22.2 \%$ of patients with active AS (BASDAI > 4) were positive for $H$. pylori in stool. In conclusion, $H$. pylori infection is associated with increased disease activity in patients with SLE and RA but not AS.
\end{abstract}

Keywords: Helicobacter pylori infection; RA; SLE; AS; Disease activity. 


\section{Introduction}

H. pylori is a widespread, spiral-shaped, flagellated Gram-negative bacterium usually infects the gastric mucosa. ${ }^{1}$ Its seropositivity increases with age as it affects about eighty percent of the middle-aged adults in the developing countries and about twenty-five to fifty percent in the western populations. ${ }^{2}$ The relation between infection and autoimmune diseases has been previously investigated. Many Gram-negative bacteria as salmonella, shigella, and chlamydia were confirmed to be associated with the development of reactive arthritis. ${ }^{3}$ These bacteria have been found to stimulate the host immune response due to the presence of lipopolysaccharides and other antigenic molecules that can cause inflammation. ${ }^{4}$ It has been previously hypothesized that $H$. pylori can induce such immune host response through many mechanisms as the molecular mimicry and antigenic similarity, disruption of the tolerogenic immune response, and activation of the polyclonal lymphocytes leading ultimately to the imbalance between T regulatory/Th17 cells in addition to the induction of autoantibody production. ${ }^{5,6,7}$

The association between $H$. Pylori and autoimmune diseases has been reported in idiopathic thrombocytopenic purpura, ${ }^{8}$ chronic idiopathic urticaria ${ }^{9}$, auto-immune thyroiditis ${ }^{10}$, autoimmune atrophic gastritis, ${ }^{11}$ and some other rheumatic autoimmune disorders as rheumatoid arthritis (RA), ${ }^{12,13,14}$ systemic lupus erythematosus (SLE) ${ }^{15}$ Sjogren syndrome, ${ }^{16}$ and ankylosing spondylitis (AS). ${ }^{17}$

On the other hand, a protective role of $H$. Pylori in some inflammatory conditions as multiple sclerosis, ${ }^{18}$ inflammatory bowel disease $^{19}$ and allergic conditions as pediatric asthma $^{20}$ has been reported. In the same context, low seropositivity of $H$. Pylori has been reported among Korean patients with HLA-B27 positive acute anterior uveitis. ${ }^{21}$

Rheumatoid arthritis, systemic lupus erythematosus, and ankylosing spondylitis are the most encountered rheumatic autoimmune diseases sharing the presence of chronic inflammation, autoantibody production, and breaking of the self-immune tolerance.
However, they are completely different in the clinical and laboratory profiles. ${ }^{22}$ Although the precise mechanism of the pathogenesis is still unknown, the genetic and epigenetic events of the host with the environmental and infectious factors resemble the most important triggering elements of autoimmunity in the three rheumatic diseases. However, there is still a controversy about the pathogenetic role of $H$. Pylori in these rheumatic autoimmune conditions, and further studies from different areas are needed to support these hypotheses. ${ }^{23}$ In this study, we aimed to evaluate the impact of the presence and activity of $H$. pylori on disease activity in patients with RA, SLE, and AS.

\section{Patients and Methods}

This study was approved by the ethics committee for medical research, Al-Azhar University, and all participants gave informed consent before enrollment in the study. This study was carried out on one hundred adult patients, randomly selected from those attending the outpatient rheumatology clinic and internal medicine department of our university hospital during the period from January 2018 to December 2019. -Patients were divided into three groups:

-Group A: (RA group): forty RA patients diagnosed according to the American college of rheumatology (ACR)-EULAR RA classification criteria 2010. ${ }^{24}$

-Group B (SLE group): forty SLE patients diagnosed according to the Systemic Lupus International Collaborating Clinics (SLICC) Classification Criteria. ${ }^{25}$

-Group C (AS group): twenty AS patients diagnosed according to the modified New York criteria. $^{26}$

Fifty healthy age and sex matched adults were selected as a control group. Any patient or control known to have treatment for $\mathrm{H}$. pylori or taking antibiotic treatment for the previous three months, patients receiving biologic therapy and those known to have diabetes mellitus, autoimmune thyroid disease or autoimmune hepatitis or any other autoimmune 
disorders were excluded from the study as well as those subjected to gastrointestinal surgery or endoscopy through the previous three months and those with pregnancy. Complete history taking and thorough clinical examination were done for each patient.

\section{Assessment of disease activity}

The following disease activity parameters were used to assess the current activity of each disease:

-Disease activity score (DAS-28) ${ }^{27}$ for patients with RA.

-SLE disease activity scale (SLEDAI) ${ }^{28}$ for patients with SLE.

-Bath ankylosing spondylitis activity index $\left(\right.$ BASDAI) ${ }^{29}$ for patients with AS.

\section{Laboratory workup}

Each patient and control were subjected to do the following laboratory investigations:

Erythrocyte sedimentation rate (ESR) was performed using the spectrophotometric assay, $\mathrm{C}$-reactive protein (CRP) by the turbidimetric method.

\section{H. pylori serum antibody assessment}

Quantitative assessment of H.Pylori antibodies (IgG) in serum was done by enzyme immunoassay (EIM). The kit was provided by MyBiosource, Southern California, San Diego (USA) cat number: MBS494432. Helicobacter antigen is bound on the surface of the microtiter strips. A binding between the Ig $G$ antibodies of the serum and the immobilized Helicobacter antigen takes place and leads to the development of a blue color. This color is changed to yellow after the addition of a stop solution and is measured spectrophotometrically at $450 \mathrm{~nm}$. Negative result was obtained if the concentration was $<8$ $\mathrm{U} / \mathrm{mL}$, equivocal if 8-12 ULmL, and positive if the concentration was $>12 \mathrm{U} / \mathrm{mL}$.

\section{H. pylori stool antigen test}

-Fresh stool samples were collected on the same day the serum antibody test was performed.
$-H$. pylori antigen was qualitatively determined in participants' stool by lateral flow immunoassay (rapid one step $H$. pylori antigen test Device, ABON Biopharm (Hangzhou), China lot number: HP0122007). In this test, the membrane was pre-coated with $H$. pylori antibodies on the test line region of the test. The antigen in the specimen was allowed to react with the particle antibody and then this mixture migrates upward on the membrane by capillary action and reacts with the $H$. Pylori antibodies on the membrane generating a colored line in the test region indicating a positive result. A colored line will appear in the control line region as a procedural control.

$-H$. pylori antigen identification in the stool is an indicator of active infection by the organism which has been reported to be a safe alternative method compared to the invasive, endoscopic biopsy examination with more than $90 \%$ sensitivity and specificity. ${ }^{30}$

\section{Statistical analysis}

Statistical package for social sciences (IBMSPSS), version 24 IBM- Chicago, USA (May 2016) was used for statistical data analysis. Data expressed as mean, standard deviation (SD), number and percentage. Mean ( \pm standard deviation) was used for the presentation of quantitative data, while number and percentage were used to describe qualitative data. One-way analysis of variance (ANOVA) test was used to compare means of the three groups of RA, SLE, and AS. Mann Whitney test was used instead of Student-t test in case of non-parametric data. Pearson Chi-square was used to compare percentages of qualitative data, and Fisher's Exact test was used for non-parametric data. Pearson correlation test was used to compare two quantitative variables. The value of $(r)$ is explained in the following figures: $r<0.2$ negligible correlation, $r \quad 0.2-0.4$ weak correlation, $r$ 0.4-0.7 moderate correlation, while, $r$ 0.7-1 = strong correlation. For all these tests, the level of significance ( $P$-value) can be explained as significance; $P<0.05$. 


\section{Results}

The mean age of patients was $36.95 \pm 10.34$ in the SLE group, $51.2 \pm 6.91$ in the RA group, and $35.5 \pm 3.71$ in the AS group while in the control group it was $48.82 \pm 5.81$. The female to male ratio was 19:1, 18:2, 1:19, and 33:17 in each group respectively. The mean $( \pm S D)$ of $H$. Pylori IgG in the serum was $0.803 \pm 0.497 \mathrm{U} / \mathrm{mL}$ in the SLE group, $1.48 \pm 0.637 \mathrm{U} / \mathrm{mL}$ in the RA group, and $0.75 \pm 0.68 \mathrm{U} / \mathrm{mL}$ in AS group while it was $0.2 \pm 0.61 \mathrm{U} / \mathrm{mL}$ in the control group with a significant difference $(P=0.000)$. The $H$. pylori antigen was found positive (indicating $\mathrm{H}$. pylori activity) in the stool of $30 \%, 70 \%$, and $20 \%$ of patients of the three groups respectively while it was positive only in $10 \%$ of the control group with a $P>0.001$. The disease activity of SLE patients (SLEDAI) was $0.6 \pm 1.6$, DAS Score was $2.97 \pm 1.05$ in the RA group, and BASDAI Score was $3.7 \pm 2.45$ in the AS group. The demographic, clinical, and laboratory data are summarized in table 1.

Table 1. Demographic data of participants.

\begin{tabular}{|c|c|c|c|c|c|}
\hline & Group A (SLE) & Group B (RA) & Group C (AS) & Control group & $P$-yalue \\
\hline & No.\% & No.\% & No.\% & No. $\%$ & \\
\hline Age (years) Mean $\pm S D$ & $36.95 \pm 10.34$ & $51.2 \pm 6.91$ & $35.5 \pm 3.71$ & $48.82 \pm 5.81$ & $<0.001$ \\
\hline \multicolumn{6}{|l|}{ Sex } \\
\hline Female & 38 (95.0\%) & $36(90.0 \%)$ & $2(5.0 \%)$ & $33(66 \%)$ & \multirow{2}{*}{$<0.001$} \\
\hline Male & $2(5 \%)$ & $4(10.0 \%)$ & 38 (95.0\%) & $17(44 \%)$ & \\
\hline $\begin{array}{l}\text { Disease duration (years) } \\
\text { Mean } \pm S D\end{array}$ & $3.22 \pm 1.23$ & $2.22 \pm 1.01$ & $1.00 \pm 0.6$ & NA & $<0.001$ \\
\hline $\begin{array}{l}\text { H. Pylori IgG in serum }(\mathrm{U} / \mathrm{mL}) \\
\text { Mean } \pm \text { SD }\end{array}$ & $0.803 \pm 0.497$ & $1.48 \pm 0.637$ & $0.75 \pm 0.68$ & $0.2 \pm 0.61$ & 0.000 \\
\hline \multicolumn{6}{|l|}{$\begin{array}{l}\text { H. Pylori Antigen in stool } \\
\text { (H. pylori Activity) }\end{array}$} \\
\hline Positive & $12(30 \%)$ & $28(70 \%)$ & $4(20 \%)$ & $5(10 \%)$ & 0.000 \\
\hline Negative & $28(70 \%)$ & $12(30 \%)$ & $16(80 \%)$ & $45(90 \%)$ & \\
\hline $\begin{array}{l}\text { Disease activity } \\
\text { Mean } \pm S D\end{array}$ & $\begin{array}{c}\text { SLEDAI Score } \\
0.6 \pm 1.6\end{array}$ & $\begin{array}{c}\text { DAS-28 Score } \\
2.97 \pm 1.05\end{array}$ & $\begin{array}{c}\text { BASDAI Score } \\
3.7 \pm 2.45\end{array}$ & NA & NA \\
\hline ESR $(\mathrm{mm} / \mathrm{h})$ Mean \pm SD & $29 \pm 17$ & $60.2 \pm 25.1$ & $52.3 \pm 18.4$ & $19 \pm 12.1$ & 0.000 \\
\hline $\mathrm{CRP}(\mathrm{mg} / \mathrm{L})$ Mean $\pm \mathrm{SD}$ & $6.8 \pm 29$ & $12.8 \pm 58$ & $9.7 \pm 12.2$ & $5.8 \pm 19.33$ & NS \\
\hline
\end{tabular}

AS: Ankylosing spondylitis, CRP: C- reactive protein, ESR: Erythrocyte sedimentation rate, RA: Rheumatoid arthritis, SLE: Systemic lupus erythematosus, NA: Not applicable, BASDAI: Bath ankylosing spondylitis disease activity index, DAS-28: Disease activity score, SLEDAI: SLE disease activity index. $P>0.05$ is not significant (NS).

Regarding the relation between $\mathrm{H}$. pylori activity and disease activity, we found that in the SLE group, $66.7 \%$ of patients who had active disease (SLEDAI >3) also had positive $H$. pylori and only $33.3 \%$ of them had negative $H$. pylori $(P=0.02)$. In the RA group, $60 \%$ of patients had moderate disease activity (DAS $28>3.2-5.1$ ) and $40 \%$ were in remission (DAS $28 \leq 2.6$ ); $83.3 \%$ of patients who had active RA also had positive $H$. pylori and only $16.7 \%$ of them had negative $H$. pylori antigen in the stool $(P=0.01)$. In AS group, $45 \%$ of patients had active disease (BASFAI $>4$ ), only $20 \%$ of them had active $H$. pylori infection $(P=$ 1.000). Data are shown in table 2 and figure 1. 
Table 2. Relationship between Helicobacter activity and disease activity.

\begin{tabular}{|c|c|c|c|c|}
\hline \multicolumn{2}{|r|}{ Groups } & \multicolumn{3}{|c|}{ Parameters } \\
\hline \multicolumn{5}{|l|}{ SLE Group } \\
\hline \multicolumn{2}{|c|}{ H.Pylori (Activity) } & \multicolumn{3}{|c|}{ Disease Activity } \\
\hline & & Inactive & Active & Total \\
\hline & Count & 26 & 2 & 28 \\
\hline \multirow[t]{2}{*}{ Negative } & \% within HP (Activity) & $92.9 \%$ & $7.1 \%$ & $100.0 \%$ \\
\hline & $\%$ within Dis Activity & $76.5 \%$ & $33.3 \%$ & $70.0 \%$ \\
\hline \multirow{3}{*}{ Positive } & Count & 8 & 4 & 12 \\
\hline & \% within HP(Activity) & $66.7 \%$ & $33.3 \%$ & $100.0 \%$ \\
\hline & $\%$ within Dis Activity & $23.5 \%$ & $66.7 \%$ & $30.0 \%$ \\
\hline \multirow{3}{*}{ Total } & Count & 34 & 6 & 40 \\
\hline & $\%$ within HP (Activity) & $85.0 \%$ & $15.0 \%$ & $100.0 \%$ \\
\hline & \% within Dis Activity & $100.0 \%$ & $100.0 \%$ & $100.0 \%$ \\
\hline \multicolumn{2}{|l|}{$* P$ value } & \multicolumn{2}{|c|}{0.011} & \\
\hline \multicolumn{5}{|l|}{ RA Group } \\
\hline \multicolumn{2}{|c|}{ H.Pylori (Activity) } & \multicolumn{3}{|c|}{ Disease Activity } \\
\hline & & Inactive & Active & Total \\
\hline \multirow[t]{3}{*}{ Negative } & Count & 8 & 4 & 12 \\
\hline & \%within HP Activity & $66.7 \%$ & $33.3 \%$ & $100.0 \%$ \\
\hline & \% within Dis. Activity & $50.0 \%$ & $16.7 \%$ & $30.0 \%$ \\
\hline \multirow[t]{3}{*}{ Positive } & Count & 8 & 20 & 28 \\
\hline & \%within HP Activity & $28.6 \%$ & $71.4 \%$ & $100.0 \%$ \\
\hline & \%within Dis. Activity & $50.0 \%$ & $83.3 \%$ & $70.0 \%$ \\
\hline \multirow[t]{3}{*}{ Total } & Count & 16 & 24 & 40 \\
\hline & \%within HP Activity & $40 \%$ & $60 \%$ & $100 \%$ \\
\hline & \%within Dis. Activity & $100 \%$ & $100 \%$ & $100 \%$ \\
\hline \multicolumn{2}{|l|}{$* P$ value } & \multicolumn{2}{|c|}{0.011} & \\
\hline \multicolumn{5}{|l|}{ AS Group } \\
\hline \multicolumn{2}{|c|}{ H. Pylori (Activity) } & \multicolumn{3}{|c|}{ Disease Activity } \\
\hline & & Inactive & Active & Total \\
\hline \multirow[t]{3}{*}{ Negative } & Count & 9 & 7 & 16 \\
\hline & \%within HP(Activity) & $56.3 \%$ & $43.8 \%$ & $100.0 \%$ \\
\hline & \% within Dis. Activity & $81.8 \%$ & $77.8 \%$ & $80.0 \%$ \\
\hline \multirow[t]{3}{*}{ Positive } & Count & 2 & 2 & 4 \\
\hline & \%within HP(Activity) & $50.0 \%$ & $50.0 \%$ & $100.0 \%$ \\
\hline & \% within Dis. Activity & $18.2 \%$ & $22.2 \%$ & $20.0 \%$ \\
\hline \multirow[t]{3}{*}{ Total } & Count & 11 & 9 & 20 \\
\hline & \% within HP (Activity) & $55.0 \%$ & $45.0 \%$ & $100 \%$ \\
\hline & $\%$ within Dis Activity & $100 \%$ & $100 \%$ & $100 \%$ \\
\hline
\end{tabular}

AS: ankylosing spondylitis, RA: rheumatoid arthritis, SLE: systemic lupus erythematosus, S: significant, NS: non-significant. $P>0.05$ is not significant (NS). ${ }^{*}$ Chi square 


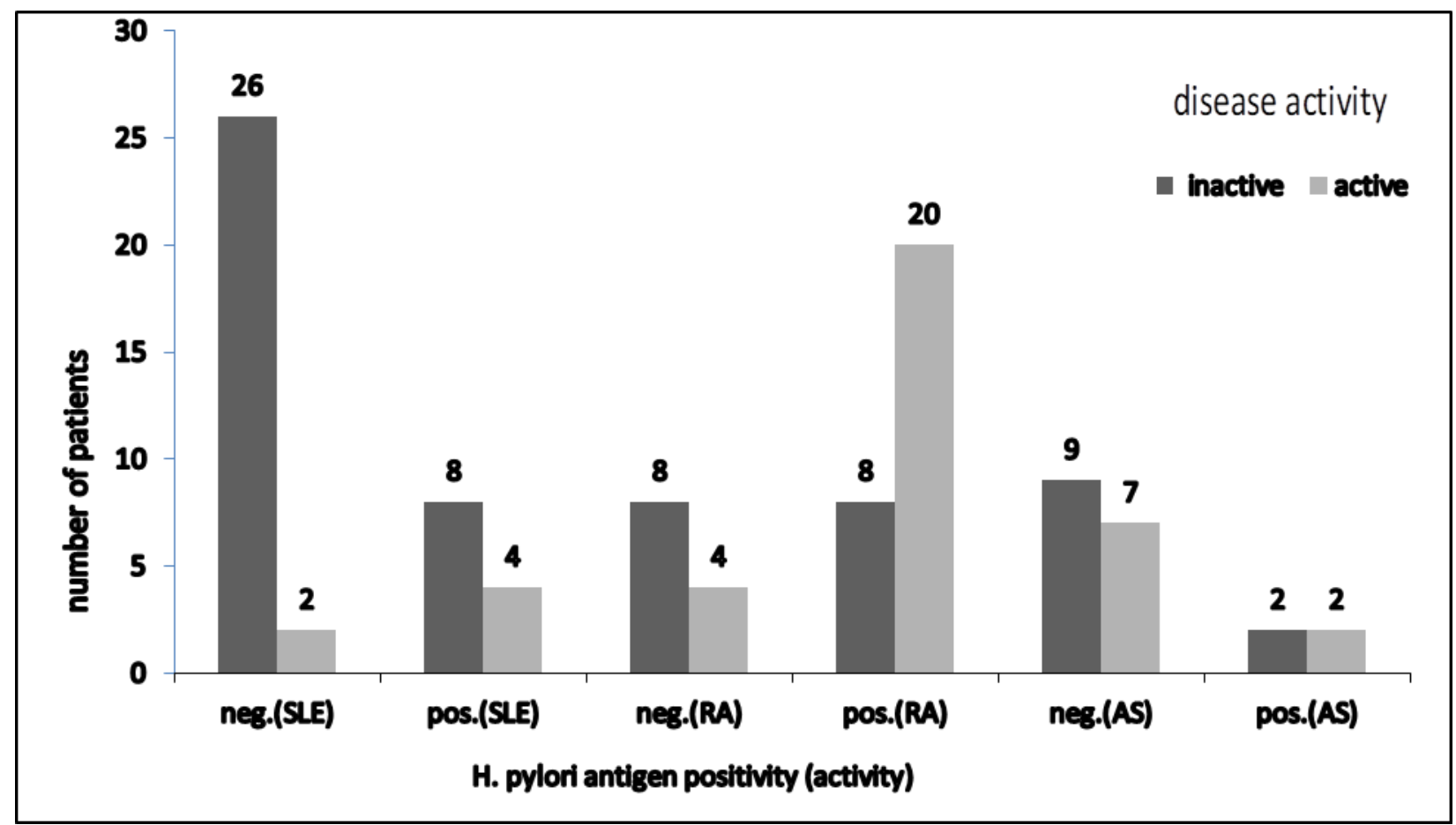

Figure1. H. pylori activity and disease activity in the three groups

\section{Discussion}

The relationship between infection and autoimmunity has been intensely investigated over the last 20 years. The immune system dysregulation and loss of immune tolerance in most systemic rheumatic diseases are suspected to be caused by many environmental effectors as infectious agents in the genetically predisposed subjects. ${ }^{31} \mathrm{H}$. pylori is one of the most common pathogens affecting humans, infecting approximately $50 \%$ of the world's population. ${ }^{32}$ To clarify the impact of $H$. pylori infection on disease activity and severity of RA, SLE and AS, this study was carried out. In the SLE group, the mean $H$. pylori level in serum was $0.803 \pm 0.497$, and the relevance of active $H$. pylori in stool was $30 \%$. Regarding disease activity, the mean SLEDAI score was $0.6 \pm 1.6$, and $15 \%$ of SLE patients in our study had active disease. Kalabay and colleagues studied the prevalence of anti-H. pylori antibodies in various autoimmune rheumatic diseases and found a comparable prevalence of $H$. pylori in SLE patients and healthy controls. ${ }^{33}$

In another study, Sawalha et al. ${ }^{34}$ compared the prevalence of $H$. pylori seropositivity in 466
SLE patients to matched controls and reported that SLE patients were less frequently positive (36.5\%) for $H$. pylori as compared with healthy controls $(42.9 \%)$ which is higher than our prevalence. They found a significant negative association for female SLE patients versus controls (38.1 versus 60.2\%; $P=0.0009$ ). It was noted that $H$. pylori seropositive AfricanAmerican females have been prone to develop SLE at an older age. In the RA group, the mean $H$. pylori level in serum was $1.48 \pm 0.637$ while the prevalence of active $H$. pylori in stool was $70 \%$ which are higher than SLE patients in this study. As regard disease activity, the mean DAS score was $2.97 \pm 1.05$ and $60 \%$ of RA patients in our study had moderately active disease. This prevalence in RA is higher than that reported by Ishikawa et al. as the prevalence of $H$. pylori infection in their RA patients was $(61.4 \%)$ in a large-scale study on 1290 Japanese subjects. ${ }^{35}$ Tanaka et al. ${ }^{36}$ reported that the seroprevalence of $H$. pylori in RA patients was $32 \%$. Also, Zentilin et al. ${ }^{37}$ reported that the seroprevalence of $H$. pylori in RA patients was $48 \%$ which is lower than our prevalence. In the AS group in our study, the mean $H$. pylori in serum was 
$0.75 \pm 0.68$ while the prevalence of active $H$. pylori in stool was $20 \%$ which is lower than the other 2 groups. Regarding disease activity, the mean BASDAI score was $3.7 \pm 2.45$, and $45 \%$ of AS patients in our study had active disease. In the current study, we demonstrated the relation between Helicobacter activity and disease activity in SLE patients and found that $66.7 \%$ of patients who had active disease also had positive $H$. pylori and only $33.3 \%$ of them had negative $H$. pylori with a significant difference.

In RA patients, we found that $83.3 \%$ of patients who had active disease also had positive $H$. pylori and only $16.7 \%$ of them had negative $H$. pylori which suggest a strong effect of $H$. pylori positivity on the severity of arthritis in RA. This was in agreement with a preliminary report of Zentilin et al. ${ }^{37}$ who reported on the effect of $H$. pylori eradication on the severity of RA. According to their results, an improvement of the analog score for RA and morning stiffness had been noticed 4 months after eradication of H. pylori. However, this improvement could be explained by many factors other than $H$. pylori. In contrast to our results, in the investigation of Ishikawa et al, ${ }^{35}$ there were no differences in the clinical severity of RA between $H$. pylori-positive and -negative patients. Additionally, Mizokami et al. ${ }^{38}$ reported that anti-rheumatic drugs didn't affect the prevalence of $H$. pylori in patients with RA. In line with our results, El-Hewala et $\mathrm{al}^{14}$, found that the fecal antigen-positive RA patients had significantly higher activity than the negative group. This is consistent with that reported by Wen et al. ${ }^{39}$ who found that patients with $H$. pylori positive have a tendency for severe clinical features characterized by an increased number of painful joints and functional impairment.

Contrarily, Matsukawa et al, ${ }^{40}$ reported that RA patients possibly could suffer from an increase in disease activity and the development of joints pain after eradication of $H$ pylori infection. They hypothesized that this eradication may lead to disruption of oral tolerance against mycobacterial heat shock protein-65. In the AS group, we found that $22.2 \%$ of patients who had active disease had positive $H$. pylori and $77.8 \%$ of them had negative $H$. pylori. This percentage was lower than the other two groups in this study. This is in agreement with a study performed by Bae et al. ${ }^{41}$ who stated that AS patients with HLA-B27positive acute anterior uveitis (AAU) had a significantly lower prevalence of $H$. pylori seropositivity compared to patients with HLAB27-negative AAU and controls. However, there was no significant difference in the prevalence of $H$. pylori seropositivity between the nonuveitis group and the control group. These results suggest an inverse relationship between H. pylori seropositivity and HLA-B27-positive AS which is in line with our results. The HLA-B27 antigen is considered closely related to $A S$, and exogenous peptides from gram-negative bacteria have been suggested to be environmental triggers for HLA-B27-positive $\mathrm{AS}^{42}$. Also, Onal et $\mathrm{al}^{43}$ reported that there was no significant association between gramnegative organisms and AS which is consistent with our findings. In contrast to our results, Huhtinen et al. and Otasevic et al. reported a possible role of gram-negative bacteria including $H$. pylori in the development and recurrence of HLA-B27-positive AS. ${ }^{44,45}$ This study has many limitations as the small sample size, the lack of confirmative invasive techniques for diagnosing $H$. pylori infection and the difficulty in correlating the individual parameters of each disease with the active $H$. pylori infection.

We concluded that, $H$. pylori infection is associated with increased disease activity in patients with RA and SLE but not in patients with AS.

\section{Author Contributions}

$A E, M R, A M, M A, M I A$, and $H A$ acquired, analyzed, and interpreted the patient data. $\mathrm{AE}, \mathrm{AM}, \mathrm{MR}$, and MIA were major contributors in writing and editing the manuscript. All authors read and approved the final manuscript.

\section{Declaration of Conflicting Interests}

The author(s) declared no potential conflicts of interest with respect to the research, authorship, and/or publication of this article. 


\section{Funding}

The author(s) denies receipt of any financial support for the research, authorship, and/or publication of this article.

\section{Ethical approval}

The study was approved by the institutional ethical committee of Al-Azhar University Hospitals -Assiut.

\section{Informed consent}

A signed consent form was obtained from each study participant.

\section{ORCID iD}

Abdelhfeez Moshrif iD https://orcid.org/0000-00017291-3616

\section{References}

1. Dang BN, Graham DY. (2017). Helicobacter pylori infection and antibiotic resistance: a WHO high priority. Nat Rev Gastroenterol Hepatol; 14(7):383.

2. Suerbaum S, Michetti P. (2002). Helicobacter pylori infection. N Eng/ J Med.; 347: 1175-1186.

3. Cooke A, Ferraccioli GF, Herrmann M, et al. (2008). Induction and protection of autoimmune rheumatic diseases. The role of infections. Clin Exp Rheumatol; 26(1 Suppl 48):1-7.).

4. Papamichael K, Konstantopoulos P, Mantzaris GJ. (2014). Helicobacter pylori infection and inflammatory bowel disease: is there a link? World J Gastroenterol WJG;20(21):6374.

5. Terao S, Suzuki S, Yaita H, et al. (2020). Multicenter study of autoimmune gastritis in Japan: clinical and endoscopic characteristics. Dig Endosc; 32(3):364 e72

6. Radic M. (2014). Role of Helicobacter pylori infection in autoimmune systemic rheumatic diseases. World J Gastroenterol WJG; 20(36):12839.

7. Chmiela M, Gonciarz W. (2017) Molecular mimicry in Helicobacter pylori infections. World J Gastroenterol; 23(22):3964.

8. Franchini M, Cruciani M, Mengoli C, et al. (2007). Effect of Helicobacter pylori eradication on platelet count in idiopathic thrombocytopenic purpura: a systematic review and meta-analysis. J Antimicrob Chemother; 60(2):237 e46.

9. Fukuda S, Shimoyama T, Umegaki N, (2004). Effect of Helicobacter pylori eradication in the treatment of Japanese patients with chronic idiopathic urticaria. J Gastroenterol;39(9):827-30.
10. Hou Y, Sun W, Zhang C, et al. (2017). Metaanalysis of the correlation between Helicobacter pylori infection and autoimmune thyroid diseases. Oncotarget; 8(70):115691

11. Minalyan A, Benhammou JN, Artashesyan A, et al. (2017). Autoimmune atrophic gastritis: current perspectives. Clin Exp Gastroenterol, 10:19.

12. Yamanishi S, lizumi T, Watanabe E, et al. (2006). Implications for induction of autoimmunity via activation of B-1 cells by Helicobacter pylori urease. Infect Immun; 74(1):248-56.

13. Matsukawa Y, Asai Y, Kitamura N, et al. (2005). Exacerbation of rheumatoid arthritis following Helicobacter pylori eradication: disruption of established oral tolerance against heat shock protein? Med Hypotheses; 64(1): 41-43.

14. El-Hewala AE, Khamis SS, Soliman SG, et al. (2015). Study of the effect of treatment of Helicobacter pylori on rheumatoid arthritis activity. Menoufia Med J; 28(2):319.

15. Wu MC, Leong PY, Chiou JY, et al. (2017). et al. (2019) Increased risk of systemic lupus erythematosus in patients with Helicobacter pylori infection: A Nationwide population-based cohort study. Front Med; 6:330

16. Chen Q, Zhou X, Tan W, et al. (20187). Association between Helicobacter pylori infection and Sjo"gren syndrome: a metaanalysis. Medicine; 97(49).

17. Inal E., Aynali A, Sanac S, et al. (2014). The impact of Helicobacter pylori antigen positivity on ankylosing spondylitis. JCAM; DOI: 10.4328/JCAM.2767.

18. Jaruvongvanich $\mathrm{V}$, Sanguankeo $A$, Jaruvongvanich $S$, et al. (2016). Association between Helicobacter pylori infection and multiple sclerosis: a systematic review and meta-analysis. Mult Scler Relat Disord; 7:92 e7.

19. Wen Z, Fiocchi C. (2004). Inflammatory bowel disease: autoimmune or immune-mediated pathogenesis? J Immunol Res; 11(3 e4):195 -204.

20. Zevit N, Balicer RD, Cohen HA, et al. (2012). Inverse association between Helicobacter pylori and pediatric asthma in a high prevalence population. Helicobacter; 17(1):30-35.

21. Bae JH, Kim JM. (2015). The Rate of Helicobacter pylori Seropositivity in a Group of Korean Patients with HLA-B27-Associated Acute Anterior Uveitis. PLoS ONE 10(4): e0123924.doi: 10.1371/journal.pone.0123924.

22. Giacomelli R, Afeltra A, Alunno A, et al. (2017). International consensus: what else can we do to improve diagnosis and therapeutic strategies in patients affected by autoimmune rheumatic diseases 
(rheumatoid arthritis, spondyloarthritides, systemic sclerosis, systemic lupus erythematosus, antiphospholipid syndromeand Sjogren's syndrome)?: the unmet needs and the clinical grey zone in autoimmune disease management. Autoimmun. Rev; 16(9):911 -24

23. Youssefi M et al., (2020). Helicobacter pylori infection and autoimmune diseases; Is there an association with systemic lupus erythematosus, rheumatoid arthritis, autoimmune atrophy gastritis and autoimmune pancreatitis? A systematic review and metaanalysis study, Journal of Microbiology, Immunology and Infection, https://doi.org/10.1016/j.jmii.2020.08.011.

24-Aletaha D, Neogi T, Silman AJ, et al. (2010). Rheumatoid Arthritis Classification Criteria: an American College of Rheumatology/European League Against Rheumatism collaborative initiative. Arthritis Rheum. 62:2569-2581.

25. Petri M, Orbai AM, Alarcón GS, et al. Derivation and validation of the Systemic Lupus International Collaborating Clinics classification criteria for systemic lupus erythematosus. Arthritis Rheum 2012; 64:2677

26. Luation of diagnostic criteria for ankylosing spondylitis. A proposal for modification of the New York criteria. Arthritis Rheum (1984); 27:361-368. doi:10.1002/art.1780270401

27. Fransen J, Riel PL. (2005). The disease activity score and EULAR response criteria. Clin Exp Rheumatol; 23:93-109.

28. Gladman DD, Ibañez D, Urowitz MB. (2002). Systemic lupus erythematosus Disease Activity Index. J Rheumatol; 29: 288-91.

29. Garrett S, Jenkinson T, Kennedy LG, et al. (1994). A new approach to defining disease status in ankylosing spondylitis: the bath

ankylosing spondylitis disease activity index. J Rheumatol, 21:2286-2291

30. Raguza D, Granato CF, Kawakami E. (2005). Evaluation of the stool antigen test for Helicobacter pylori in children and adolescents. Dig Dis Sci; 50(3): 453-7

31. Amital H, Govoni M, Maya R, et al. (2008). Role of infectious agents in systemic rheumatic diseases. ClinExpRheumatol; 26: S27-S32.

32. Marshall, B.J. and J.R. (1984). Warren, Unidentified curved bacilli in the stomach of patients with gastritis and peptic ulceration. Lancet, 1(8390): p. 1311-5.

33. Kalabay, L., et al., (2002). Helicobacter pylori infection in connective tissue disorders is associated with high levels of antibodies to mycobacterial hsp65 but not to human hsp60. Helicobacter, 7(4): p. 250-6. 34. Sawalha, A.H., et al. (2004). Association between systemic lupus erythematosus and Helicobacter pylori seronegativity. J Rheumatol, 31(8): p. 1546-50.

35. Ishikawa, N., et al. (2002). Helicobacter pylori infection in rheumatoid arthritis: effect of drugs on prevalence and correlation with gastroduodenal lesions. Rheumatology (Oxford), 41(1): p. 72-7.

36. Tanaka, E., et al., (2007). Nonsteroidal antiinflammatory drug use does not affect short-term endoscopic and histologic outcomes after Helicobacter pylori eradication in patients with rheumatoid arthritis. Mod Rheumatol,. 17(3): p. 22834.

37- Zentilin, P., et al., (2002). Eradication of Helicobacter pylori may reduce disease severity in rheumatoid arthritis. Aliment Pharmacol Ther,. 16(7): p. 1291-9.

38- Mizokami, Y., et al., (1994). Non-steroidal antiinflammatory drugs associated with gastroduodenal injury and Helicobacter pylori. Eur J Gastroenterol Hepatol, 6 Suppl 1: p. S109-12

39- Wen, H., et al. (2012). Helicobacter pylori infection in rheumatic diseases. Arthritis research \& therapy, 14(1): p. P74.

40- Matsukawa, Y., et al. (2005). Exacerbation of rheumatoid arthritis following Helicobacter pylori eradication: disruption of established oral tolerance against heat shock protein? Med Hypotheses, 64(1): p. 41-3.

41- Bae, J.H. and J.M. Kim, (2015). The Rate of Helicobacter pylori Seropositivity in a Group of Korean Patients with HLA-B27-Associated Acute Anterior Uveitis. PLoS One, 10(4): p. e0123924.

42- Hasni, S.A., (2012). Role of Helicobacter pylori infection in autoimmune diseases. Curr Opin Rheumatol. 24(4): p. 429-34.

43- Onal, S., et al., (2006). Prevalence and levels of serum antibodies to gram negative microorganisms in Turkish patients with HLA-B27 positive acute anterior uveitis and controls. Ocul Immunol Inflamm, 14(5): p. 293-9.

44- Otasevic, L., et al. (2007). Helicobacter pylori: an underestimated factor in acute anterior uveitis and spondyloarthropathies? Ophthalmologica, . 221(1): p. 6-13.

45- Huhtinen, M., et al., (2002). Infectious background of patients with a history of acute anterior uveitis. Ann Rheum Dis, 61(11): p. 1012-6. 